\title{
The Use of Language by Parents to Express Disability in Saudi Arabia
}

\author{
Dr. Mashael Suliman Alariefy \\ Abstract \\ This study investigates the use of language to express disability; by \\ parents of children with disability in Riyadh, Jeddah and two rural \\ areas. An analysis of this theme is based upon qualitative data \\ collected from 42 semi-structured individual and group interviews \\ with the parents. \\ The findings suggest that all parents have refused the terms 'disabled' \\ or 'child with a disability', some of them gave alternative terms. \\ Parents gave an indication about the domination of the medical model \\ of disability through the language they used in the interviews. \\ In the light of this study, it is recommended that the media and \\ governmental officials have to raise awareness and spread a positive \\ attitude towards disability in the society. Similary the positive \\ language towards disability from social media can play a crucial role \\ in raising awareness. \\ Keywords \\ Disability, children with disability, mothers of children with disability, \\ fathers of children with disability, disability model, medical model, \\ language, qualitative study, semi-structure interview.
}




\section{1- Introduction}

A family can be considered to be the initial structure for the running and ruling of all human societies (Brown and Brown, 2003). Crow and Allan (2000) emphasise the central place occupied by the family as an organisation that delivers social care for its members within a civil society.

The attitude of others may create different obstacles or facilitators that influence the life of people with disability (Guscia et al., 2006). The parents are the closest people to their children with disability, often living together in the same house and therefore sharing the same life circumstances. Because of this, the attitude of these parents can affect significantly the lives of the children due to reasons that include the implicit relationship between them. However, parents' attitude can be changed (Rose, 2010). So, the disability model that parents are adopting has a huge impact on their children.

\subsection{Research Motivation}

Despite the efforts to define disability, the interpretations that families have are useful as a reflection of the societal attitudes toward people with disability (Ferguson, 2002). The language of a society may give an indication of its attitude. Since the families of children with disability are a part of the society, it can therefore be expected that they will adopt the same attitudes of the community, which can be inferred through the vernacular phrases that are used.

\subsection{Study's Aims, Questions and hypothesis:}

This study aims to investigate the use of language by parents of children with disability to express disability.

Meeting this aim will require the consideration of two key study questions:

1- How do parents understand the term "disability"

2- How to explore the disability model through parents' language?

"The language that is used in expressing disability can be an indication to what extent disability is accepted" is the hypothesis for this study.

\section{2: Literature Review}

\subsection{Definitions of disability}

Although the word 'disabled' is commonly associated with the image of a person in a wheelchair, a large variety of disabilities exist (Hume, 1994). Consequently, it should be unsurprising that there are many

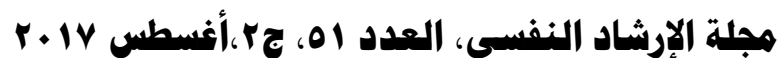




\section{Dr. Mashael Suliman Alariefy}

definitions of disability; one of the most popular of which is from the World Health Organisation (WHO), which identifies a disability as "any restriction or lack 'resulting from any impairment' of ability to perform an activity in the manner or within the range considered normal for a human being" (WHO, 1976: 8). The Disability Discrimination Act (DDA) of 1995 in the UK describes disability as "A physical or mental impairment which has a substantial and longterm adverse effect on a person's ability to carry out normal day-today activities" (DDA, 1995: 2).

In the context of Saudi, according to the King Salman Center for Disability Research (KSCDR), the Disability Code provides the following understanding of disability:

A person with a disability is one who is totally or partially disabled with respect to his/her bodily, material, mental, communicative, academic or psychological capabilities, to the extent that it compromises the ability of that person to meet his/her normal needs as compared to his/her nondisabled counterparts.

(KSCDR, 2000: 20)

In addition to the use of the word 'normal', which can be deemed unacceptable due to its vagueness and because it cannot be measured or evaluated, the Saudi Disability code omitted the stipulation for disability to be substantial and long-term in nature. Therefore, this research adopts the DDA definition. The language that is used in definitions is crucially important, not only because it shapes and limits meaning, but also because it illustrates the particular thoughts and beliefs at that time that it was coined. As Hume notes, "language is critical in shaping and reflecting our thoughts, beliefs, feelings and concepts. Some words by their very nature degrade and diminish people with a disability" (Hume, 1994: 3).

In Saudi contact, agencies such as media and universities, view the term 'disabled person' as being inappropriate and therefore tend to avoid its use (Al-Jadid, 2013). In an attempt to make this study more acceptable to Saudi society, as well as making it clear to readers in Saudi Arabia which group of people I am focusing on, I have elected to use the term 'person with disability' in my research.

Some societies use terms that reflect undesirable perceptions, such as crippled, lame, invalid, retarded, and moron, all of which suggest

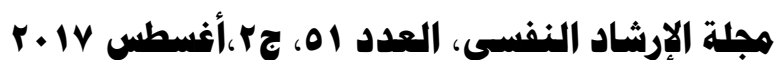


inferiority of the subject, or evoke pity or fear of the person with disability (Roush, 1986). Supporting this position, Graham (2006) argues that terms such as cripple, lame and invalid may have been acceptable in the past, but are now considered to be insensitive and hurtful. Graham adds that terms like handicap and handicapped should also no longer be used unless in citation for laws. This evolution of terms can result in confusion regarding the correct ways with which to describe individuals. For example, research suggests that efforts by the British government to define 'disability' have not completely addressed confusion among parents regarding 'disability' and 'special educational needs', and whether or not these terms apply to their children (Lewis et al., 2007).

Besides the definition of disability, it can be useful to understand disability through a review of the evolution of the concept through time. In any society, the current concept of disability will necessarily be the result of accumulations and developments that have arisen from previous understandings.

\subsection{Historical background}

People with disability and the rights to which they are entitled have passed through difficult times such as oppression, marginalisation or segregation. Myriad differences have been observed between cultures in respect to people with disability, with individuals with disabilities being rejected in some cultures, like India; exiled, as occurred in some Greek city states in the sixth century; or kept alive by their families, but perceived as economic burdens, as occurs in some Eskimo communities (Hanks, 1948).

In the Western world, during the 17th and early 18th centuries, people with disabilities were often hidden away and could even be disowned by their families, eventually being allowed to die because the means to properly support a person with disability were rarely available (Fleischer and Zames, 2011). This seemed to be the survival of the strongest. However, in Arab countries, justice for people with disability can be traced back as far as the seventh century. One of the most famous Islamic stories tells of Allah admonishing his Prophet Muhammad, because of how he treated a blind man. People used to consider the limping and blind people as being repulsive, leading them to avoid sharing food with them (Al-Jadid, 2013). When Prophet Muhammad was busy inviting some highly positioned men to Islam, a

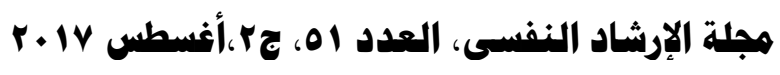




\section{Dr. Mashael Suliman Alariefy}

blind poor man approached the prophet and asked him a question about Islam. Muhammad turned his head and did not answer the blind man's question because he was busy with the other men. In the holy Quran, this is written as follows:

-1- The Prophet frowned and turned away -2- Because there came to him the blind man, [interrupting]. -3- But what would make you perceive, [O Muhammad], that perhaps he might be purified -4- Or be reminded and the remembrance would benefit him? -5- As for he who thinks himself without need, -6- To him you give attention.

Allah's castigation of his prophet, Muhammad, can still be read from the holy Quran today. At that time, the instructions from the holy Quran and the prophet Muhammad, were sufficient to create an inclusive community in the Hejaz region of the Arabian Peninsula, which contains the city of Jeddah. This community was compatible with the needs of life at that time, which did not have the complexity of requirements and luxuries as modern society.

In the Western world, the 19th century saw a very slow movement towards the rights of people with disability and their families. In the 1850 s, reformers began to open large institutions for people with severe learning disabilities, which were very popular for almost a century (Leiter, 2004).

Looking back at the situation in the nineteenth century it seems evident that people with disability were perceived as being a burden on their families and their communities. In addition, the desire to isolate them from society and limit their numbers were common and even dominant views. However, from the second half of 20th century, the development of services and support systems for people with disability experienced a profound shift, from taking those with disability from their family and leaving them in institutions, to empowering the same individuals to participate in society by working and living like any other citizen (Braddock, 2002).

\subsection{Disability models}

An examination of the historical perceptions of disabilities suggests that there has been a shift of emphasis from the individual to the social, which has enabled a wide-ranging critique of the ways in which society views people with disability (Priestley, 2003). This has led to the development of various disability models, to describe and

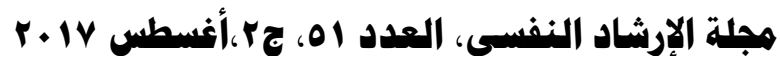


understand the presence of different attitudes with regards to disability (ibid). The models are a way of conceptualising a situation.

The focus of the medical model has classically been on diagnosing and attempting to cure disability. In this model, a disability was regarded as a tragedy (Johnstone, 1998; Marks, 1998). In order to meet this objective, this model divides people with disability into categories and gives them labels according to their diagnoses and abilities. According to this model, services and support were aimed to 'fix' the individual and to eliminate the disability. In the medical model, it is not the responsibility of the society to adapt to the potential of a given individual (Oliver, 1996).

Some went beyond this stance and linked disability with punishment from God (Thornton, 1987). This view may be old and may still be believed by superstitious people, by those who have a simple view of causation, or those who believe in fatalism (Sandow, 1994). However, it is almost certainly a much rarer belief in the modern world (Avoke, 2002).

During the mid-twentieth century, there was a deviation from the medical model of disability, with the shift moving towards the view of disability within a societal context. In this model, social context plays a crucial role in understanding the disability, meaning that the environment has to be reformed (Marks, 1998) and societal barriers have to be fixed or changed, rather than the individuals with disability (Braddock, 2002; Shakespeare, 1997). The social model places the duty of supporting those people with a disability on the community, in terms of both the physical environment and general social behaviour (Brandon and Pritchard, 2011). Marchant and Jones (1999) think that many of the difficulties facing people with disabilities arise due to society's beliefs, the arrangements of services and the behaviour of adults. Many studies emphasise the importance of news media in the social construction of reality (Gamson, 1992). In fact, Haller et al., (2010) go so far as to argue that the news media act as an obstacle for inclusion, since reporting typically presents disability in relation to the medical model. However, in the modern context, the service system has evolved and people with disability and their families are no longer viewed as needing to be fixed, instead needing to be supported (Samuel et al., 2012).
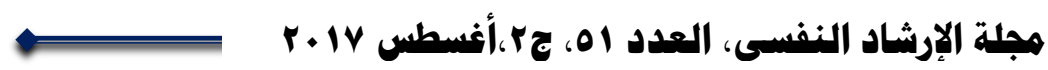

$(10 \leqslant)$ 


\section{Dr. Mashael Suliman Alariefy}

Ultimately, in the Western world, the beginning of the provision of systematic services for people with disabilities was considerably later. since the first special schools in western world opened in the 1700s (Adams et al., 2007). In contrast, the situation in the Arabian Peninsula, which is now Saudi Arabia, did not provide any systematic services until 1960, when the first school opened for people with visual impairment (Almosa, 2007). Regarding family support, the push towards recognising the role of the family of children with disability and ensuring the provision of support has resulted in the steady growth of provision of services for people with disabilities in the Western world. In contrast, the position in Saudi Arabia is more limited, with the first independent centre to support families of people with disabilities only opening in 2010.

\section{3: Methodological Framework}

The selection and use of an appropriate research methodology plays a vital role in managing the research, in determining how data will be collected, and in ensuring that data will address the aims of the research (Salehi and Golafshani, 2010).

Adopting qualitative methods for collection and analysis of data allows an in-depth investigation of research questions and phenomena, enabling them to be understood through discovering, exploring, developing and testing various assumptions about social reality (Miles and Huberman, 1994)

Creswell (2003: 22) argues that if "a concept or phenomenon needs to be understood because little research has been done on it, then it merits a qualitative approach". Therefore, the qualitative research method chosen for my research is interviewing. This approach has been chosen to gain as much information as possible, to enable the research questions to be investigated in-depth and to therefore better understand the real situation.

\subsection{Types of Interview}

In qualitative research, individual interviews are considered the most widely-used data collection approach (Nunkoosing, 2005). Research interviews with individuals are usually divided into three types: structured interviews; semi-structured interviews; and unstructured or in-depth interviews (Saunders et al., 2009).

In order to ensure a deeper understanding of opinions and views about all the considered themes, but while ensuring that control of the
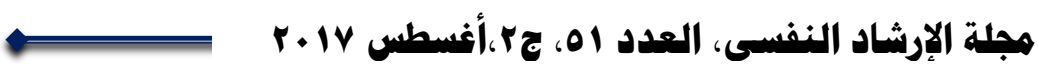
interview is not lost, this research utilised the semi-structured interview strategy with the participants. Each interview consisted of a number of carefully chosen set of closed questions, gathering important but predictable information, such as the age of the child or the education level of the parent. These are followed by open-ended questions, giving the opportunity for new questions to be raised during the course of the interview.

Semi-structured interviews can provide important and sensitive data (Fielding, 1993; Hall and Hall, 1996). Besides the sensitive data, the information can be rich and detailed due to the presence of the openended questions. Moreover, it is a flexible method in questioning and answering because the interviewer has the opportunity to ask for clarification and the interviewer can stimulate discussion and extend some points (Frankfort-Nachmias and Nachmias, 1996; Morgan, 1997).

It has been argued that the practical application of semi-structured interviews means that they are as viable to use with groups as they are with individuals (Merton, 1956). Morgan (1997: 23) also states:

Focus groups and individual interviews can be complementary techniques across a variety of different research design in particular, either of them can be used in either a preliminary or a follow-up capacity with the other. This illustrates the larger point that the goal of combining research methods is to strengthen the total research project, regardless of which method is the primary means of data collection.

The combination of interviewing methods, such as individual interviews and focus groups, has to be for a reason, that is, to strengthen the research, but it does not matter how it is conducted in the first place as long as the decision is justified. The combination of methods helps to enable the creation of a wide image and to address some gaps in knowledge that cannot be filled through the use of one method (Morgan, 1997). This use of multiple methods enables the use of triangulation, which is when more than one method is used to gain the same information to increase the reliability of the research and strength the trustworthiness of the findings (Kvale, 1996; Denzin and Lincoln, 2005).
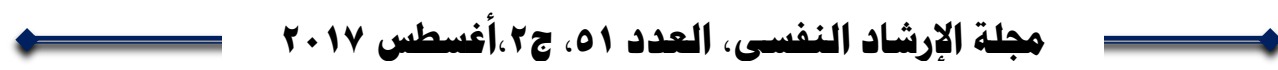


\section{Dr. Mashael Suliman Alariefy}

\subsection{Participants}

I used the snowball sampling technique (May, 2011; Miles and Huberman, 1994), since I needed to rely on social contacts, interviewees, and professional networks in Saudi Arabia to act as intermediaries to contact resource persons and potential informants.

Kvale (1996: 101) advises researchers to "interview as many subjects as necessary to find out what you need to know". The number of participants in qualitative research can be small or large, depending on the research subject and the point at which further interviews will not offer additional information (ibid). Barrett and Cason (1997: 106) add that "when you begin hearing (and believing) the same answers over and over again", this should signal the end of the data collection task. This point, at which data does not add any depth to the topic, is known as 'saturation' (Strauss and Cobrin, 1998: 212). Regarding focus groups, Vaughn at al. (1996) suggest that groups be kept small and manageable, typically comprising 6-12 members.

In my research, I have 42 participants, 20 of whom participated in one-to-one interviews. In Jeddah, I talked with 4 mothers and 4 fathers; a further 4 mothers and 4 fathers were interviewed in Riyadh; and 2 mothers and 2 fathers from more remote regions also took part. I then conducted six focus groups. Four of these were groups of mothers: 2 in Jeddah and 2 in Riyadh, each with 4 participants. The remaining two focus groups contained fathers: the first in Jeddah and the remaining group in Riyadh, each with 3 participants.

In my participants, there were no requirements for the level of education or the social class and I was able to achieve a very good level of variation, as mentioned in the aforementioned section on triangulation. In the focus groups, Vaughn et al. (1996) argue that one of the core elements of a focus group is that its members should be relatively homogeneous, such as in terms of the ages or types of disability of children. The members of each focus group in my research came from the same city and all have children with disabilities; moreover, due to the uniqueness of each culture, each focus group consisted only of individuals of the same sex.

Regarding triangulation, I interviewed 42 parents; there were parents of children with Down's Syndrome, autism, learning disability, physical disability, hearing disability, visual disability, and children with multi-disability. There were also parents of children with mild,

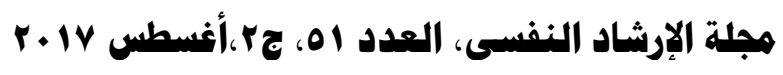


moderate and severe disability. The age of the children in the sample ranged from 4 months to 17 years [see table 1, 2]. Additionally, there were parents of children with disability as the only child, first child, last child, middle child, those with a twin, those with a sibling who has the same disability, and children who have a sibling with a different disability.

Table (1)

a list of fathers that were interviewed

The fathers: $\mathrm{F}=$ fathers, $\mathrm{R}=$ Riyadh, $\mathrm{J}=\mathrm{Jeddah} \mathrm{U}=$ rural area $\mathrm{G}=$ group, $\mathrm{I}=$ individual

\begin{tabular}{|c|c|c|c|c|}
\hline Code & $\begin{array}{c}\text { Type of } \\
\text { interview }\end{array}$ & $\begin{array}{c}\text { Child } \\
\text { Gender/age }\end{array}$ & Type on disability & Any comment \\
\hline FRI-1 & Individual & $\mathrm{G} / 15$ & Spina bifida & The only girl between boys \\
\hline FRI-2 & Individual & $\begin{array}{l}\mathrm{B} / 13 \\
\mathrm{~B} / 10 \\
\mathrm{~B} / 8\end{array}$ & Visual disability & $\begin{array}{l}\text { They have one big brother } \\
\text { without disability. Their } \\
\text { mother is [MRG-6] }\end{array}$ \\
\hline $\begin{array}{l}\text { FRI-3 } \\
\text { Activist }\end{array}$ & Individual & $\mathrm{B} / 11$ & $\begin{array}{c}\text { Cerebral palsy caused } \\
\text { quadriplegia }\end{array}$ & In the middle \\
\hline $\begin{array}{l}\text { FRI-4 } \\
\text { Activist }\end{array}$ & Individual & $\mathrm{B} / 9$ & Autism & In the middle \\
\hline FRG-5 & Focus group & $\mathrm{B} / 7$ & Autism & The only child \\
\hline FRG-6 & Focus group & $\mathrm{G} / 5$ & Autism & In the middle \\
\hline FRG-7 & Focus group & $\mathrm{B} / 13$ & $\begin{array}{l}\text { Hemiplegia at the age of } \\
\text { five as a result of } \\
\text { infection }\end{array}$ & In the middle \\
\hline FJI-1 & Individual & $\mathrm{G} / 7$ & Atrophy of the brain & $\begin{array}{l}\text { Her eldest sister died, she has } \\
\text { younger sister }\end{array}$ \\
\hline FJI-2 & Individual & $\mathrm{B} / 9$ & $\begin{array}{c}\text { Atrophy of the brain and } \\
\text { Quadriplegia }\end{array}$ & He is the eldest \\
\hline FJI-3 & Individual & $\mathrm{G} / 8$ & Spina bifida & In the middle \\
\hline FJI-4 & Individual & G/11 & Cerebral palsy & $\begin{array}{l}\text { The only child. Her mother is } \\
\text { [MJI-4] }\end{array}$ \\
\hline FJG-5 & Focus group & $\mathrm{G} / 9$ & Cerebral palsy & Has twin without disability \\
\hline FJG-6 & Focus group & $\mathrm{B} / 9$ & $\begin{array}{l}\text { Brain edema, weak bones, } \\
\text { spine deviation, Speech } \\
\text { difficulties and learning } \\
\text { disability }\end{array}$ & The last child \\
\hline FJG-7 & Focus group & $\mathrm{G} / 13$ & $\begin{array}{l}\text { Complete paralysis after } \\
\text { car accident when she } \\
\text { was } 3 \text { moths }\end{array}$ & $\begin{array}{l}\text { Her mother and sister died in } \\
\text { the accident, she has sisters } \\
\text { from step mother }\end{array}$ \\
\hline FUI-1 & Individual & $\mathrm{B} / 6$ & Autism & The only child \\
\hline FUI-2 & Individual & $\mathrm{G} / 4$ & $\begin{array}{l}\text { Home accident caused } \\
\text { damage in brain }\end{array}$ & The only girl between boys \\
\hline
\end{tabular}

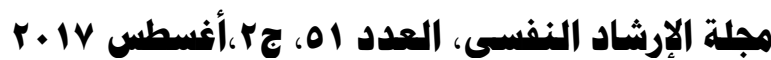




\section{Dr. Mashael Suliman Alariefy}

Table (2)

a list of mothers that were interviewed

The mothers: $\mathrm{M}=$ mothers, $\mathrm{R}=$ Riyadh, $\mathrm{J}=\mathrm{Jeddah} \mathrm{U}=$ rural area $\mathrm{G}=$ group, $\mathrm{I}=$ individual

\begin{tabular}{|c|c|c|c|c|}
\hline Code & $\begin{array}{c}\text { Type of } \\
\text { interview }\end{array}$ & $\begin{array}{c}\text { Child } \\
\text { Gender/age }\end{array}$ & Type on disability & Any comment \\
\hline $\begin{array}{l}\text { MRI-1 } \\
\text { Activist }\end{array}$ & Individual & $\mathrm{B} / 11$ & Down's Syndrome & The last child \\
\hline MRI-2 & Individual & $\begin{array}{l}\mathrm{B} / 17 \\
\mathrm{G} / 11\end{array}$ & Hearing disability & The last two children \\
\hline MRI-3 & Individual & $\mathrm{B} / 6$ & Down's Syndrome & The last child \\
\hline MRI-4 & Individual & $\begin{array}{c}\mathrm{G} / 9 \\
\mathrm{G} / 4 \mathrm{monthes}\end{array}$ & $\begin{array}{c}\text { Visual disability Spina } \\
\text { bifida }\end{array}$ & $\begin{array}{c}\text { Have two sisters without } \\
\text { disability }\end{array}$ \\
\hline MRG-5 & Focus group1 & $\mathrm{G} / 10$ & Down's Syndrome & The last child \\
\hline MRG-6 & Focus group1 & $\begin{array}{c}\mathrm{B} / 13 \\
\mathrm{~B} / 10 \\
\mathrm{~B} / 8\end{array}$ & Visual disability & $\begin{array}{l}\text { They have one big brother } \\
\text { without disability }\end{array}$ \\
\hline MRG-7 & Focus group1 & $\mathrm{B} / 7$ & Down's Syndrome & The last child \\
\hline MRG-8 & Focus group1 & $\begin{array}{c}\mathrm{G} / 10 \\
\mathrm{~B} / 4\end{array}$ & $\begin{array}{l}\text { The girl muscular atrophy } \\
\text { and learning difficulties. } \\
\text { The boy Cerebral palsy }\end{array}$ & $\begin{array}{c}\text { They have a sister without } \\
\text { disability }\end{array}$ \\
\hline MRG-9 & Focus group2 & $\mathrm{B} / 13$ & Spina bifida & The last child \\
\hline $\begin{array}{l}\text { MRG- } \\
10\end{array}$ & Focus group2 & $\mathrm{B} / 10$ & Spina bifida & In the middle \\
\hline MRG11 & Focus group2 & $\mathrm{B} / 4$ & Spina bifida & The only child \\
\hline MRG12 & Focus group2 & $\mathrm{B} / 12$ & Cerebral palsy & In the middle \\
\hline MJI-1 & Individual & B6 & Cerebral palsy & The last one \\
\hline MJI-2 & Individual & $\mathrm{B} / 16$ & Learning disability & The last one \\
\hline MJI-3 & Individual & $\begin{array}{c}\mathrm{B} / 8 \\
\mathrm{~B} / 20 \text { months }\end{array}$ & White matter disease & $\begin{array}{c}\text { They have big brother } \\
\text { without disability }\end{array}$ \\
\hline MJI-4 & Individual & $\mathrm{G} / 11$ & Cerebral palsy & The only child \\
\hline MJG-5 & Focus group1 & $\mathrm{B} / 4$ & Cerebral palsy & $\begin{array}{l}\text { The first child and has } \\
\text { brother without disability }\end{array}$ \\
\hline MJG-6 & Focus group1 & $\mathrm{B} / 2$ & Cerebral palsy & $\begin{array}{l}\text { The first child and has } \\
\text { brother without disability }\end{array}$ \\
\hline MJG-7 & Focus group1 & $\mathrm{B} / 6$ & Cerebral palsy & The only child \\
\hline MJG-8 & Focus group1 & $\mathrm{B} / 4$ & Cerebral palsy & In the middle \\
\hline MJG-9 & Focus group2 & $\mathrm{G} / 14$ & Down's Syndrome & $\begin{array}{l}\text { In the middle and has } \\
\text { twin without disability }\end{array}$ \\
\hline $\begin{array}{l}\text { MJG-10 } \\
\text { Activist }\end{array}$ & Focus group2 & $\mathrm{B} / 12$ & Autism & The last child \\
\hline MJG-11 & Focus group2 & $\mathrm{G} / 11$ & Hearing disability & The first child \\
\hline MJG-12 & Focus group2 & $\mathrm{B} / 6$ & Down's Syndrome & The first child \\
\hline MUI-1 & Individual & $\mathrm{G} / 6$ & Atrophy of the brain & In the middle \\
\hline MUI-2 & Individual & $\mathrm{G} / 8$ & Atrophy of the brain & She has younger sister \\
\hline
\end{tabular}

Table 2: a list of mothers that were interviewed

There were also parents of children in special schools, in mainstream schools with full or partial integration, children who did not go to

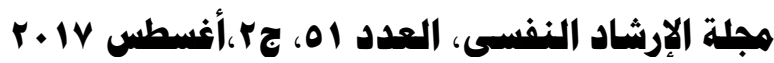


school at all, and some went for a short period then they stayed at home. There were young parents who are still university students, retired parents, resigned parents, mothers as housewives, parents working in the government sector, those working in the private sectors, and those working as businessperson. The education of parents spanned from uneducated parents, including some with limited education, to those with graduate degrees. Some from wealthy families, the most were from average families and there were families with low income. Although a few parents belong to a tribe, others do not. I interviewed two couples but separately. I interviewed divorced mothers, mothers in the process of divorce, wives of men who have more than one wife and I interviewed single parents due to the death of the wife or because the husband was in prison.

\section{Findings}

Almost all participants, both mothers and fathers, refused to use the terms 'disabled' or 'child with a disability', although a small number of parents used the term 'children with disability' during the interview. However, these uses only occurred when they referred to other children and not their own, which will not be taken into account because it is clear it was a reflection of the phrases that I used as an interviewer. However, they did not perceive any difference between the terms 'child with disability' and 'disabled child'. A father [FRG-7] said "Are we fooling each other? This is only a play on words". The reasons that they provided for the refusal of the two terms varied to an extent. For example, some parents showed a lack of understanding of the word disabled. As one mother [MJG-6] said:

The word 'disabled' cannot be used to describe our children. It means a person who is not fully capable mentally and physically. I used to have a sister and she passed away; she was disabled, not my son.

Although her son is in a wheelchair and the centre that her son attends contains the phrase 'disabled children' in its name, the mother never told her son that he could be considered disabled. Similarly, one father [FJG-6] stated that "My son is not disabled, he can walk, disabled is just a word for people in wheelchairs". His 9-year-old son can hardly walk; has splints on his feet; cannot move one of his hands and only moves the other with difficulty; cannot talk; and has learning difficulties. However, these parents seem to believe that the term

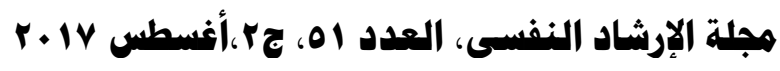




\section{Dr. Mashael Suliman Alariefy}

'disabled' does not apply to their children. A number of other parents refuse to use the term without giving any reason. One mother [MRG7] said "I will not accept the word disabled, I consider my son to be normal, and I do not care what the others think".

The use of the word 'normal' by the mother gives the impression that she believes that children with disabilities are abnormal and she is therefore afraid that her son will be classified in this category. This fear makes her insist on continuing to refer to her son as being 'normal' regardless of the opinion of others.

Some of the parents thought it was an insult to the child. For example, one mother [MJI-1] said:

Thank God I haven't met anyone who said my son is disabled, despite the fact that some of the mothers told me that there are people who call their children disabled. What a shame.

She was talking about the term as being a bad word, even though her son is in a centre that has the words 'disabled children' in its name. Another mother [MRI-3] expressed her feelings by saying: "The word disabled is harmful to the child and his parents. When I see centres with the word disabled, I feel pain". The son of this woman has Down's syndrome and goes to a special school, however the name of the school does not contain the word disabled as most of the private centres. One of the mothers [MRG-11] raised a point worth considering:

I used to refuse the word disabled, but after a conversation with Muhammad Alsheref, who is active on Twitter and has a disability, I changed my mind. I think that the term 'person with disability' is acceptable, but you know the problem is the use of the word disabled in our society. A broken chair we call a disabled chair, a stupid idea is a disabled idea, when we gather as a family they say to the one who wasn't sitting properly: correct this disabled pose. Often I get annoyed.

In this comment, she shed light on an important aspect of the linguistic culture of Saudi society. Since I belong to this society, I can confirm that in the vernacular, anything faulty can be referred to as disabled. In fact, it is extremely common to use the word disabled in

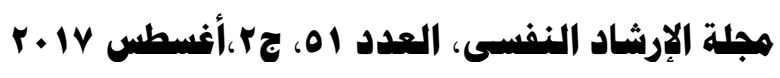


ironic comments and jokes, while the use of this term to a person with a disability is often intended to underestimate him or her.

Indeed, all of the parents refused to consider the use of the term 'disabled', although they did not agree on an alternative. Many preferred 'child with special needs', but there are other labels such as 'gifts of God'. On this matter, a mother [MRG-5] of a daughter with Down's Syndrome said:

We, as a group of mothers, decided to call our children Gifts of God because we think they are gifts that bring happiness and blessing to our lives.

One father [FRG-7] prefers the name chosen by his son, explaining that "My son is 13 years old, he has an Instagram account on which he introduces himself as a person with special features". One mother [MRG-11] thinks the best term is "challenged children", in reference to the numerous challenges that she believes will fill their lives. Another mother [MRG-9] refused all of the terms and said, "He has a name and people can call him by his name, no need for those terms at all". A father [FRI-2] said "they can use phrases such as 'integration children.' They are not disabled or special needs". This father has three children with vision disabilities and no learning difficulties. It may therefore be that the father chose the terms that are linked to education because it is a reflection of the most important concern for the father, which is teaching his sons and preparing them for life. He believes in their capability, but complains about the educational services available to them.

It is clear that there is no agreed-upon name for individuals with disability, although most of the participants prefer 'people with special needs'. Many of the parents refer to their children by saying that they are tired or ill; some of them used the phrase 'not normal'. Ironically, a mother [MUI-1] who refuses the word disabled used "Mongolian child" when she talked about a child with Down's Syndrome. I think that there is a strong argument to suggest that the media plays a big role in promoting 'people with special needs' as a way to respect people with disabilities. On other hand, they consider using 'disabled person' or 'person with disability' as a disrespectful way of treating them. On World Disabled Day 2013, the debates in social media in Saudi Arabia principally concentrated on two topics: what name should be used to refer to people with disabilities and

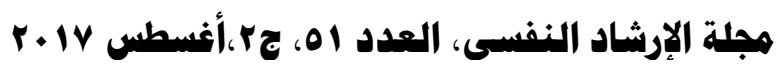




\section{Dr. Mashael Suliman Alariefy}

parking issues. Despite persons with disabilities themselves being present on social media, asking for more important discussion, such as about the creation of a suitable work environment for them, the aforementioned topics received the largest share of attention. Moreover, programmes in the official media also typically promoted the medical model by presenting special schools as being the best place for a child with disability.

Indeed, this attitude of parents towards disability is influenced by a number of factors, which will be raised in the next section.

The issue of which term to use was not the only one that preoccupied the interviewees. Many parents were not convinced that their child's disability is permanent, which had potentially far reaching consequences in the way they behaved.

In the interviews, most of the parents referred to the disability as a disease, using phrases such as [FJG-6] "My son has had this disease since birth" or [FJI-2] "Medical error is causing this disease in my child". One parent [MRG-12] even said, "When someone asks me about my son, I tell him he is ill, just pray for him". There are different reasons why the words 'disease' and 'ill' are used. In the Saudi Arabian context, linguistic culture is one likely reason, as it is popular in the kingdom to use 'disease' and 'ill' in many cases where they are not technically correct. All types of disability can be referred to as illnesses. This term is also used for psychiatric disorders, even when the community believes they are cursed by an evil eye, bewitching or even possession. Moreover, because parents avoid the use of 'disability' and 'disabled', the easiest alternative might be using common terms such as 'disease' and 'ill'. After all, it is important not to marginalise the concept of the word 'disease' and its association with healing, as well as its potential impact on parents' understanding of disability.

A father [FUI-1] of a child with autism said: "I did not leave out any hospital in Riyadh; I went to all of them. I want a cure for my son". This family lives in a small town about an hour and a half from Riyadh by car. His search for a cure for his son obligates him to visit Riyadh daily for consecutive weeks. "Why does my child has to be disabled all her life? I need someone to tell me where I can get a cure in any country". This father [FJI-4] was speaking about his belief that a cure for his daughter must exist somewhere in the world. His

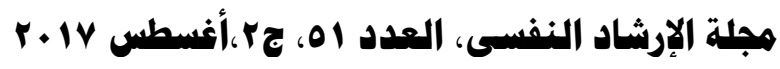


daughter has cerebral palsy due to a lack of oxygen at birth. Her father has travelled to Jordan, the Czech Republic, and Dubai; now he is preparing to visit America. This idea was not exclusive to this father; many shared his idea from a religious perspective. One mother [MUI1] said the following:

Prophet Muhammad said, 'Allah does not send down any disease, but $\mathrm{He}$ also sends down the cure for it.' I know there is a treatment for my daughter; it is my responsibility to look for it.

All Muslims believe in this Hadith [Hadith means a quote by the Prophet Muhammad], so if parents consider disability to be a disease, it is reasonable that they would search for a cure.

In fact, even those parents who are aware of the difference between disease and disability may still be controlled by the idea of the pursuit of a cure as a solution. An activist father [FRI-3] of a child with quadriplegia said, "Now my obsession is stem cells; it seems to solve everything". I think that this interest is acceptable in situations in which it does not negatively impact upon the family or the child. Parents of children with Down's Syndrome did not mention a cure in their interviews; none of them were looking for a cure, but they had other concerns relating to behaviour modification and skills development. This may be explained by the nature of the disability, since it is a defect in chromosomes and thus it is evident that it cannot be altered.

One father [FJI-3] talking about his opinion on abortion explicitly said:

Unfortunately, we discovered a disability in the advanced stages of pregnancy. If it had been earlier, we would not have hesitated to abort the foetus, for the child himself and his family, but also for the society as a whole. The fire burns just the foot of he that stands on it [famous aphorism]; no one can imagine life with a disabled child except his parents.

This father explained that a child with a disability is a burden on different levels, while he thinks that nobody will understand the tragedy that his family is experiencing except for the family itself. Therefore, it can be anticipated that the father will not wait for support
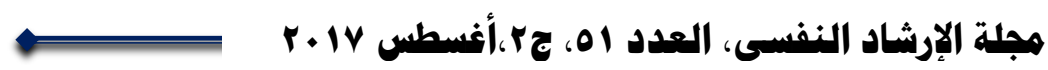


\section{Dr. Mashael Suliman Alariefy}

because he is convinced that no one understands the situation enough to provide it.

My first problem was with the mother; she did not accept the situation of our son. But she changed completely after entering a treatment centre with our son for eight weeks. Now she has fully accepted our son's disability after seeing children similar to our son and worse. If you see others' disasters, your disaster will be eased.

The last part "If you see others' disasters, your disaster will be eased" of the father's words [FJI-2] is a very famous aphorism that was mentioned by many of the parents in their interviews. This expression means that they need to see children with more severe disabilities than what their own children have before they will be able to properly accept it.

All parents spoke of their shock when the disability was discovered in their first child and how long it took them to believe it. The issue of having the first child with the disability was raised by many parents, a father [FJI-2], who has a nine-year-old child with a disability, said:

In fact, if the woe occurred in the first child, it will be very difficult, for us the situation was very bad until God gave us the second child and he was a healthy child.

Despite the use of the word 'woe' in describing the disability, the father clearly showed his reaction of shock when he learned that he would be having a child with a disability, noting the surprise and the factors that helped to relieve this shock. He considered having a healthy child as a relief. This may be due to the parents feeling like failures with their first child, so giving birth to a healthy child restores their confidence in themselves and before society.

All parents mentioned the importance of religion in accepting the disability at least twice in their talk; they all agreed upon the need to accept that the disability had been sent by God. "I believe in God, she is from God, and I am satisfied with that", these were the words of one of the parents [FRI-1], which were repeated by almost all of the participants, although often in different wording. However, while some considered the disability as a gift from God, others considered it to be a test. One mother [MJI-4] said, "God would not put this disability in my way unless it is good for me". This idea has a religious basis, as Islam holds that all things, whether good or bad, are

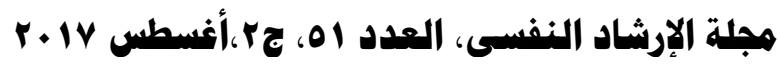


in the interest of the believer. One father [FJI-3] said, "We counted the awards from God. She is a blessing; when she came to us, our condition improved financially and emotionally". This is one of the core tenets of the Islamic religion: namely that God will reward good conduct in such situations in the afterlife. Many parents cited this Hadith, which comes from the word of the Prophet Muhammad, "When God loves a certain people He tests them". They think God is testing their patience and satisfaction by giving them a child with a disability. [MJG-8] "My son is of God and I am satisfied, but people bother me when they look piteously to him and think he is a misfortune". In fact, religious people may be harsher in their beliefs and judgement on the child and his parents.

People around me think that my son is a punishment from God because they believe that I have oppressed my uncle's wife by assisting her husband to have another wife... but I know myself, I even did not laugh at any one with a disability or taunted him... I just say All praise is due to Allah who saved me from that which $\mathrm{He}$ has afflicted you with.

As the mother [MJG-5] explained, people around this mother attributed this belief to this reason only. In addition, they believed that her divorce from her husband had occurred due to the same reason. However, it must be taken into account that this mother used to live in a village with a closed society where most of the residents are from the same family and have limited education, as is the case in most Saudi villages. Another mother [MJG-6] said:

People bother me when they see my child as a scourge of God, but the reality is that he is light and a blessing of God in my life, even at the level of my relationship with my husband.

It may be that the words of this mother are slightly exaggerated, as she is the first wife. Because her husband has another wife, he only visits her home once a week. As mentioned earlier, men in Saudi Arabia can have up to four wives at the same time. She said that except the financial support, she marginalised him from her life and the lives of her children. This may not be incompatible with her first words: the woman was going to divorce, but she preferred to continue the

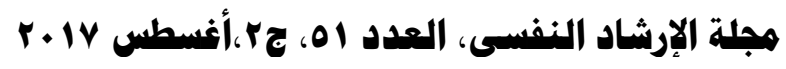




\section{Dr. Mashael Suliman Alariefy}

marriage after having a child with a disability, as she believed that this would result in an improvement in her relationship with her husband. However, it is hard for her to show that the situation was unpleasing. In the religious culture of Saudi society, one must show satisfaction in front of others, because acting the opposite way might make people sceptical with regards to the degree of your religiosity.

Because of this, fatalism plays a big role in the parents' beliefs. Even if they do not believe in something, they cannot say so because objection and discontent of fate and destiny are unacceptable in the religious Saudi society. Thirteen years after a car accident, a father [FJG-7] said:

Having a baby born with disability is different from having your child become disabled due to a traffic accident. This accident also took my wife and my lovely oldest daughter; they died. My situation is different from the rest, but thank God, it is our fate; I do not want to talk about that.

In fact, he was the only father who confessed to being uncomfortable talking about his daughter. Even when he participated in the discussion with the focus group, he expressed this idea by saying, "This wound inside me and talking about it will open it again and cause me pain". Perhaps because of this, he ended up leaving the group a little earlier than the others.

\section{Discussion}

This study found that while most of the parents realise that their children have a disability, all of the participants oppose the use of the term 'disabled' and most of them also refused the use of other alternatives, such as the term 'with disability'. Some parents state that their child is 'normal', while others associated the term disability with someone being on a wheelchair and so refused to use it for their own son or daughter. Hume (1994) supports this assertion, having widely identified that although there are many different disabilities, the word 'disabled' is generally associated with the image of a person in a wheelchair.

In order to clarify to which extent the community refuses the use of the term 'disabled', some parents of children who use wheelchairs think that this word only describes those with severe physical and mental disabilities, rather than simply describing children on

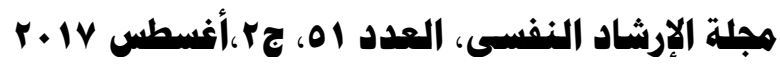


wheelchairs. This contradicts Hume's view above. Therefore, many parents seem to believe that this term is like a stain and they are trying to avoid the use of this label for their children.

Parents who believe that their children have a disability still refuse to use the terms 'disabled' and 'with disability'. They believe that those terms are insulting and the majority tend to use the term 'with special needs' instead. It should be noted that using terms such as crippled, lame, invalid, retarded and moron is thought to reflect undesirable perceptions in some societies, which may lead to inferiority, or evoke pity or fear from the people with disability (Roush, 1986). In the Saudi society, the word 'disabled' can also be added to the list of unacceptable words.

The language of scholars and the media may have contributed to this idea. The concept of refusing terms can be affected by the language used publically or by scholars, although in some cases these authorities have emphasised that the use of such terms can be inappropriate. Moreover, the colloquial Arabic use the words 'disabled' and 'with disability' by linking them with being unsuccessful, whether or not they are tangible objects, ideas or behaviours. This gives the impression to casual listeners that these words should be considered offensive.

Islam can be considered the primary guidance of Saudi society. I found that the words 'disabled and with disability' were not mentioned in the holy Quran or in the words of the Prophet Muhammad, which is a likely reason for some Saudi parents to avoid using them. However, none of the participants mentioned any part of the Quran that uses the word 'disability', meaning that neither of these terms 'disabled and disability' derives legitimacy from religion. However, the words 'blind', 'lame' and 'weak' can be found in the context of some religious commitments, such as praying in the mosque. This has a few different interpretations in Islam and is typically referenced to the suffering and pain that the disability may experience, which entitles them to a greater reward in the afterlife.

On the system level, it is interesting to note that the Ministry of Social Affairs, which has the primary responsibility for people with disabilities, uses the word 'disabled' in their official publications and on their website. The official website of the Ministry includes 'Disabled Care' as one of the main sections, for example, their travel

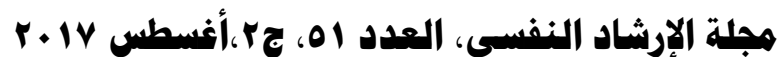




\section{Dr. Mashael Suliman Alariefy}

card is entitled with 'Discount Card for Disabled Passengers'. However, although these words do occur, most of the written news on the ministrys' website uses the term 'with special needs' (MOSA, 2015).

It can be concluded that the influence of the community and media has even shaped the language used by the editors at the Ministry of Social Affairs. The ministry has failed to influence its employees and even the parents, since all of the papers sent to parents by the ministry still utilise the term 'disabled', as well as the registration form and the social research form. The paper required by parents to prove their case also uses the word 'disabled' in its title, regardless the word is widely rejected by parents.

Parents tend to use words such as 'disease' and 'ill' in reference to both the disability and their child who has that disability. However, this is not merely a linguistic device, the data show that many parents continue to deal with disability as a disease and therefore they give the issues of medical treatment first priority. This behaviour, which reflects the dominance of the medical model of disability in Saudi society, is discussed more in the next section.

The strong expressions used by parents to talk about the situation provide an interesting insight into their perceptions. Some of the mothers and fathers claimed to see the situation of having a child with a disability being in a fire, explaining that nobody will understand their difficulties except those who stand in that fire as they do. Others think of it as a lamentable situation, using terms such as 'woe' and mentioning that having another child without disability can provide a measure of solace for them. The explanation for this might be that parents could regain confidence in themselves when they find that they are able to give birth to a child without a disability. In the US, it was common in the 1800 s to view a child with a disability as the fault of the parents, however this view became less prevalent in the early 20th century (Ferguson, 2002). Apparently, this way of thinking about disability still exists among some parents in modern day Saudi Arabia. From the religious perspective, many parents are devout Muslims and therefore see their child with a disability as being a message from God. This message can sometimes serve as a 'test' or a 'punishment', or even as a 'gift'. In any case, in order to not question their faith in God's will, these parents can only show their satisfaction with having

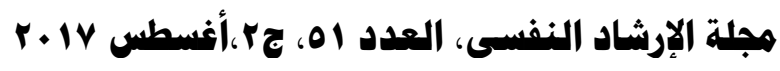


this child. Fatalism is one of the pillars of the Islamic religion. It stresses the importance of accepting all events and actions, such as marriage and death, including the disability of oneself or a family member. Because of this, parents cannot show their anger or dissatisfaction in front of others, because this would be an unacceptable behaviour that demonstrates the weakness of their faith. The more religious people believe in the sayings of the Messenger of Allah, who said: "Wondrous is the affair of the believer for there is good for him in every matter and this is not the case with anyone except the believer. If he is happy, he thanks Allah and there is good for him. If he is harmed, he shows patience and there is good for him". These parents believe that their child has been given their condition for the good of the family, ensuring a reward from God for their patience, support and the care that they give to them. Many parents mentioned the idea of patience and divine reward during their interviews.

This correlates with the findings about the general beliefs that parents have about disability. In the Saudi context, a disability is believed to be a punishment, a test or a blessing. Avoke (2002) thinks that the concept of disability as punishment is generally an outdated one, although this concept still exists in communities that believe in superstitions, who have unsophisticated view of causation, or fatalistic communities (Sandow, 1994). The findings of this study suggest that this way of thinking is still widespread in rural Saudi Arabia. Moreover, some Saudi people think that making fun of a person with a disability can be a logical reason to result with a similar disability, or to have a child with a disability. A very common prayer exists for this, which people usually say when they see a person with a condition that they do not like, such as a disability, diseases such as leprosy, or even a bad behaviour. Prophet Muhammad said: "Whoever sees an afflicted person then says: "All praise is due to Allah who saved me from that which He has afflicted you with and blessed me greatly over many of those whom He has created". While a large number of hadith scholars have questioned the credibility of this source, it remains very popular at all levels, and has been mentioned on numerous occasions in the interviews. Those parents who see disability as a test of their patience from God derive conviction from the former words of the Prophet, who said: "He shows patience and there is good for him". This

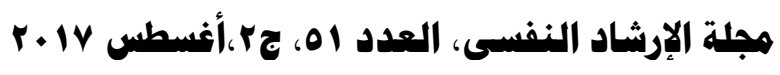




\section{Dr. Mashael Suliman Alariefy}

conviction is often linked to the belief that God has chosen the family to have a child with a disability because He knows that they are able to afford it, in the words of the Quran: "Allah does not charge a soul except 'with that within' its capacity". Therefore, some parents stated that they see the child with a disability as a blessing from God because of the positive changes that they have experienced in their life, such as improved economic situation or increasing convergence between parents.

This also gives an indication about the lack of acceptance of the situation. From the parents point of view, this is a tragedy and requires a medical solution, which again reflects the dominance of the medical model.

Parents' views reflected the ideas of the medical model of disability, such as seeing the disability as a disaster, which places an emphasis on disability as a tragedy (Johnstone, 1998; Marks, 1998) or as the responsibility of the individual (Oliver, 1996). It could be argued that such views may effectively prevent them from developing a wider and a better understanding of what needs to be changed in society in order to include children with disability. This conceptualisation has the potential to be applicable to other societies that share the same traditions, beliefs, culture, religion and customs with Saudi Arabia, such as the other countries of the Arabian Gulf. By understanding the conceptualisation of disability in Saudi Arabia, plans can be developed to guide its society towards a more effective social model. The following are the most prominent features of the medical model in Saudi.

\section{Conclusion}

In order to find significant answers to its research questions, this research adopted a qualitative approach. In order to explore the views of adults on a personal, sensitive subject, semi-structured interview were conducted with 42 participants selected using the snowball sampling technique. Interviews were held with individuals and focus groups in cities of Riyadh and Jeddah, as well as two rural areas.

The findings show the domination of medical model of disability among parents of children with disability in Saudi Arabia. This position can be applied on the Saudi society since families of children with disability are an important part of it.
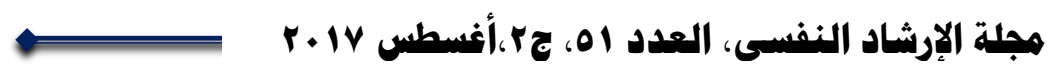

(IVI) 
The word "disabled" is used negatively in Saudi Arabia, therefore, the parents refused to use it on their children despite the fact it is used in the official documents, media, and schools' names. Some participants viewed their childrens disability as a disease or an illness; indicating that it is a temporary situation and can be treated while the word disabled indicates it being permanent. The terms "disabled" and "child with disability" were both rejected by almost all of the participants due to the lack of understanding and awareness yet an alternative was not suggested.

Based on the above, it shows the importance of the community's movement from the medical model to the social model, which can be achieved through concerted efforts among government and private sectors as an early step to improve and develop the situation of people with disabilities in Saudi Arabia.

"Disabled " or "with disability " both should be acceptable. It is one of the roles of the media and governmental officials to raise awareness in accepting people with their differences.

The fact that some parents think that their children are diseased or ill is affecting them negatively because parents will do everything to heal their children rather than accepting them as they are and focusing on the educational and behavioural sides of their live. Which will hinder the process of merging them into society. Therefore, awareness should be raised in this matter as well.

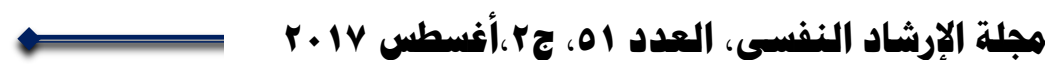




\section{Dr. Mashael Suliman Alariefy}

\section{References:}

1. ADAMS, M., BELL, L. A. \& GRIFFIN, P. 2007. Teaching for diversity and social justice, New York ; London, Routledge.

2. AL-JADID, M. S. 2013. Disability in Saudi Arabia. Saudi Medical Journal, 34, 453-460.

3. ALMOSA, N. 2007. Kingdom's experience in integrating children with special educational needs in mainstream schools. Special Education Conference III: early intervention, challenges and ambitions. Doha: Ministry of Education.

4. AVOKE, M. 2002. Models of Disability in the Labelling and Attitudinal Discourse in Ghana. Disability \& Society, 17, 769777.

5. BARRETT, C. B. \& CASON, J. W. 1997. Overseas research : a practical guide, Baltimore ; London, Johns Hopkins University Press.

6. BRADDOCK, D. 2002. The state of the states: Public policy toward disability at the dawn of the 21st century, Washington, DC, American Association on Mental Retardation.

7. BRANDON, T. \& PRITCHARD, G. 2011. 'Being fat': a conceptual analysis using three models of disability. Disability \& Society, 26, 79-92.

8. BROWN, I. \& BROWN, R. I. 2003. Quality of life and disability : an approach for community practitioners, London, Jessica Kingsley.

9. CRESWELL, J. W. 2003. Research design : qualitative, quantitative, and mixed methods approaches, Thousand Oaks, Calif. ; London, Sage.

10. CROW, G. \& ALLAN, G. 2000. Communities, Family Support and Social Change. In: J. CANAVAN, P. D. A. J. P. (ed.) Family Support: Direction from Diversity. London: Jessica Kingsley.

11. DDA 1995. Disability Discrimination Act 1995 : a consultation on the employment code of practice, guidance on definition of disability and related regulations, Great Britain, Department for Education and Employment.

12. DENZIN, N. K. \& LINCOLN, Y. S. 2005. The SAGE handbook of qualitative research, Thousand Oaks ; London, Sage Publications.

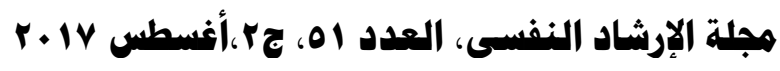


13. EA 2010. Equality Act 2010: Elizabeth II. Chapter 15. London: Stationery Office.

14. FERGUSON, P. M. 2002. A Place in the Family: An Historical Interpretation of Research on Parental Reactions to Having a Child with a Disability. Journal of Special Education, 36, 124.

15. FIELDING, N. 1993. Qualitative Interviewing. In: GILBERT, G. N. (ed.) Researching social life. London: Sage.

16. FLEISCHER, D. Z. \& ZAMES, F. 2011. The disability rights movement : from charity to confrontation, Philadelphia, Pa., Temple University Press.

17. FRANKFORT-NACHMIAS, C. \& NACHMIAS, D. 1996. Research methods in the social sciences, London, Edward Arnold.

18. GAMSON, W. A. 1992. Talking politics, Cambridge, Cambridge University Press.

19. GRAHAM, S. 2006. Diversity: Leaders not labels, New York, Free Press.

20. GUSCIA, R., EKBERG, S., HARRIES, J. \& KIRBY, N. 2006. Measurement of Environmental Constructs in Disability Assessment Instruments. Journal of Policy and Practice in Intellectual Disabilities, 3, 173-180.

21. HALL, D. J. \& HALL, I. M. 1996. Practical social research : project work in the community, Basingstoke, London.

22. HALLER, B., RALPH, S. \& ZAKS, Z. 2010. Confronting obstacles to inclusion: how the US news media report disability. In: ROSE, R. (ed.) Confronting Obstacles to Inclusion: International Responses to Developing Inclusive Education. London: Routledge.

23. HANKS, J. R. \& HANKS, L. M. 1948. The Physically Handicapped in Certain Non-Occidental Societies. Journal of Social Issues, 4, 11-20.

24. HUME, J. 1994. Media Guidelines, Sydney, Disability Council of NSW.

25. JOHNSTONE, D. 1998. An introduction to disability studies, London, David Fulton Publishers.

26. KVALE, S. 1996. Interviews : an introduction to qualitative research interviewing, Thousand Oaks, Calif., Sage Publications.

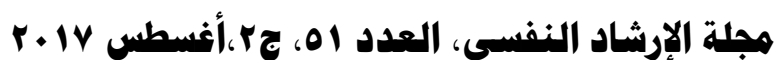




\section{Dr. Mashael Suliman Alariefy}

27. LEITER, V. 2004. Parental Activism, Professional Dominance, and Early Childhood Disability. Disability Studies Quarterly, 24, $1-16$.

28. LEWIS, A., DAVISON, I., ELLINS, J., NIBLETT, L., PARSONS, S., ROBERTSON, C. \& SHARPE, J. 2007. The experiences of disabled pupils and their families. British Journal of Special Education, 34, 189-195.

29. MARCHANT, R. \& JONES, M. 1999. Practice Guidance on Assessing Disabled Children and their Families' in The Framework for the Assessment of Children in Need and their Families. Department of Health

30. . Does It Hurt to Care? Caregiving, Work-Family Conflict, and Midlife Well-Being. Journal of Marriage and Family, 60, 951966.

31. MAY, T. 2011. Social research : issues, methods and process, Maidenhead, Berkshire, Open University Press.

32. MERTON, R. K. 1956. The focused interview : a manual of problems and procedures, [S.1.], The Free Press.

33. MILES, M. B. \& HUBERMAN, A. M. 1994. Qualitative data analysis : an expanded sourcebook, Thousand Oaks, Calif. ; London, Sage.

34. MORGAN, D. L. 1997. Focus groups as qualitative research, Thousand Oaks ; London, SAGE.

35. MOSA. 2015. The approval of the Custodian of the Two Holy Mosques to replace the programme of cars [Online]. MOSA. Available:

https://translate.google.com.sa/?hl=en\&tab=wT\#en/ar/The\%20ap proval $\% 20$ of $\% 20$ the $\% 20$ Custodian $\% 20$ of $\% 20$ the $\% 20$ Two $\% 20 \mathrm{H}$ oly $\% 20$ Mosques $\% 20$ to $\% 20$ replace $\% 20$ the $\% 20$ program $\% 20$ of $\% 2$ 0cars [Accessed 28-7 2015].

36. NUNKOOSING, K. 2005. The problems with interviews. Qualitative Health Research, 15, 698-706.

37. OLIVER, M. 1996. Understanding disability : from theory to practice,

38. PRIESTLEY, M. 2003. Disability: A life course approach, Oxford, BlackwellPublishing.

39. KSCDR 2000. Disability code in Saudi Arabia, Riyadh, King Salman Center for Disability Research

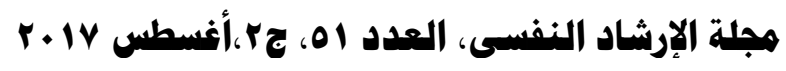


40. ROSE, R. 2010. Confronting Obstacles to Inclusion : International Responses to Developing Inclusive Education. 1 ed. London: Routledge.

41. ROUSH, S. E. 1986. Health Professionals as Contributors to Attitudes Toward Persons with Disabilities: A Special Communication. Physical Therapy, 66, 1551-1554.

42. SALEHI, K. \& GOLAFSHANI, N. 2010. COMMENTARY: Using mixed methods in research studies: An opportunity with its challenges. International Journal of Multiple Research Approaches, 4, 186-191.

43. SAMUEL, P. S., HOBDEN, K. L., LEROY, B. W. \& LACEY, K. K. 2012. Analysing family service needs of typically underserved families in the US . Journal of Intellectual Disability Research, 56, 111-128.

44. SANDOW, S. 1994. More ways than one: models of special needs. In: SANDOW, S. (ed.) Whose Special Need?: Some Perceptions of Special Educational Needs. London: Paul Chapman Publishing.

45. SAUNDERS, M., LEWIS, P. \& THORNHILL, A. 2009. Research methods for business students, Harlow, Financial Times Prentice Hall.

46. SHAKESPEARE, T. 1997. Rules of engagement: changing disability research. In: BARTON, L. \& OLIVER, M. (eds.) Disability studies past, present and future. Leeds: The Disability Press.

47. STRAUSS, A. L. \& CORBIN, J. M. 1998. Basics of qualitative research : techniques and procedures for developing grounded theory, Thousand Oaks, Calif., Sage.

48. THORNTON, L. R. 1987. counseling Problems of a Family Whose Child Has Muscular Dystrophy. Calvary Baptist Theological Journa, 3, 5-17.

49. VAUGHN, S., SCHUMM, J. S. \& SINAGUB, J. 1996. Focus group interviews in education and psychology, Thousand Oaks ; London, SAGE.

50. WHO 1976. disability prevention and rehabilitation, Geneva, Switzerland, World Health Organisation.

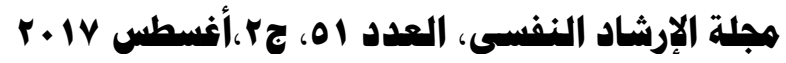

